physiology. Gluck had attempted after years of experimental work to restore the form and function of chronically diseased joints. Although these attempts failed, they represent the work of a pioneer whose diverse and original research deserves recognition.

We thank the department of medical photography, Derriford Hospital, Plymouth; Dr H Bunn for help with translation; and Ms $\mathrm{H}$ Frame for typing the manuscript.
1 Wessinghage D. Themistocles Gluck: 100 Jahre kunstlicher Gelenkersatz. Z Orhop 1991;129:383-8.

2 Muster D. Themistocles Gluck, Berlin 1890: a pioneer of multidisciplinary applied research into biom Dentistry 1990;38:3-6.

(implation. Berliner Klinische Wochenschrift 1881:18:529.

4 Zippel J, Meyer-Ralfs M. Themistocles Gluck (1853-1942) Wegbereiter der Endoprothetik. Z Orthop 1975;113:134-9.

5 Gluck T. Referat über die durch das moderne chirurgische. Langenbecks Archio fir Klinische Chinurgie 1891;41:187-239.

6 Lange F. Themistocles Gluck: zum 80 Geburtstag. Munich: Münchener Medische Wochenschrift; 1933.

\title{
Doctors differ over the German crown prince
}

\author{
Pierce A Grace
}

"The doctors determined to make him unconcious, and to carry out the removal of the larynx without having informed him of their intention. I raised objections, and required that they should not proceed without his consent. ... His father, after being informed by me, forbade them to carry out the operation without the consent of his son." The objections to the proposed treatment were raised by Otto von Bismark, the chancellor of Germany, and the throat the doctors proposed to cut was that of the 56 year old German crown prince and future Emperor, Frederick William of Hohenzolleren.

\section{Simply a cold}

In January 1887 Frederick became hoarse and had considerable difficulty in clearing his throat. It was thought at first that he simply had a cold, but when the symptoms persisted his physician, Surgeon-General Wegner, asked Dr Gerhardt, professor of medicine in Berlin, to examine him. On 6 March Dr Gerhardt diagnosed a small growth on the left vocal cord but was unable to say whether or not it was malignant. He attempted to remove the growth surgically-first with a snare and then a ring knife. Failing in this, he simply cauterised the growth with the galvano-cautery and advised Frederick to go to Ems on the north German coast to recover. From there, in April 1887, Frederick's wife, Vicky, wrote to her mother, Queen Victoria: “All the irritation, swelling and redness is fast subsiding, he never coughs, and has not the feeling of soreness, but part of the little 'granula' which Professor Gerhardt could not take off with the hot wire, because the throat was too much irritated is still on the surface of one of the Stimmbänder and will have to be removed when we go home, then I think that the hoarseness will quite disappear."2

On their return to Berlin in May Gebhardt found that the growth was larger and the voice hoarser than ever. A surgeon, Professor Ernst von Bergmann, gave his opinion that the growth should be removed by thyrotomy - that is, splitting the larynx and removing the growth. Vicky wrote again to her mother: "The idea of a knife touching his dear throat is terrible to me. Of course Fritz is as yet not to know a word about this."' This plan was too much even for Bismark, who disliked the liberal anglophilic Fritz and found his interference in politics and state affairs irksome. But the thought of the doctors rendering the crown prince unconscious without his permission was anathema to the chancellor. He intervened and another consultation was held. Professor Tobold, a senior Berlin laryngologist, and five other doctors gave their opinion that the prince had cancer and that the surgical operation proposed by Bergmann should be undertaken. It was not. Yet another opinion was sought.

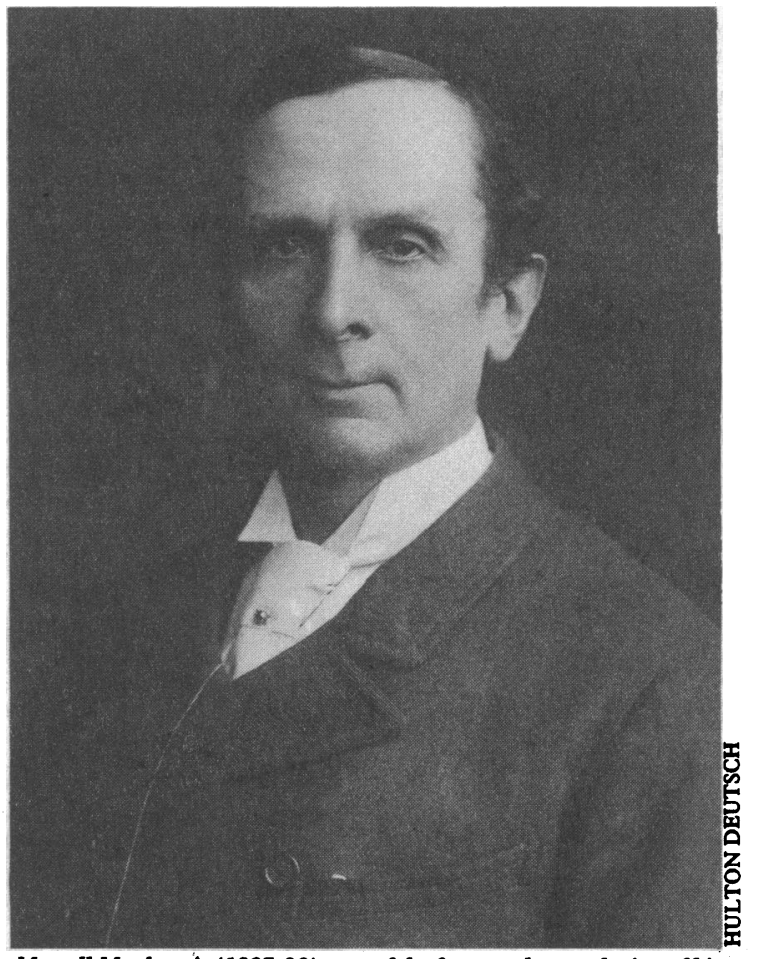

Morrell Mackenzie (1837-92), one of the foremost laryngologists of his day, was summoned to Berlin to examine the throat of the crown prince, Frederick William of Hohenzolleren

Dr Morell Mackenzie was one of the foremost laryngologists of his day. After graduating from the London Hospital College, he studied in Paris, Prague, and Vienna and in 1859 learnt from Professor Czermak the use of a recently invented instrument, the laryngoscope. ${ }^{3} \mathrm{He}$ was the first Englishman to become expert in operations on the larynx and he had a huge private practice in London. He had helped found the Hospital for Diseases of the Throat in 1863 and he had written several books and articles on otolaryngology; his Manual of Diseases of the Throat and Nose published in two volumes in 1880 and 1884 was a standard textbook. Mackenzie was summoned to examine the royal throat.

\section{No operation necessary}

Morell Mackenzie was no diplomat, and trouble wasn't long in coming. On his arrival in Berlin on the evening of 20 May 1887 he examined Frederick's throat and announced that he was not sure that an operation was necessary. The following day he took a biopsy specimen and sent it to Virchow, who said that the specimen was inadequate but that there was no malignancy in the small piece he had examined. The German doctors maintained that the clinical behaviour 
of the growth indicated cancer and that the operation should go ahead. Mackenzie disagreed and demanded histological proof before operating. He resolved to take another specimen but decided that the German instruments were not good enough and sent to England for his own.

Gerhardt described the biopsy: "I saw him take the forceps from his breast pocket and introduce it without previous cleansing; whilst he was introducing it the light ... fell on the cheek, instead of the mouth. The forceps came back empty.",

Another specimen was subsequently submitted to Virchow, who described the issue as a "superficial shred of mucous membrane" and reported that no malignancy could be detected. ${ }^{4}$ On 25 May the proposal to operate was abandoned, albeit under protest from Gerhardt and Bergmann. Just how bad relations between the doctors had become can be guessed at from the accusation levelled at Mackenzie that he deliberately took the second specimen from the normal right vocal cord.

\section{Ominous warning}

Mackenzie was anxious that his patient come to England and be treated "like an ordinary mortal." The crown princess, who seemed to be making most of the decisions and siding, not unreasonably, with the more hopeful prognosis of her fellow countryman, agreed. She wrote, "We are much more hopeful and reassured about Fritz's throat now. ... [Dr Morell Mackenzie] thinks he can cure Fritz quite well by treating his throat from the inside. ..." 2 Dr Gerhardt reexamined Frederick in June and found that the growth had spread to the other vocal cord. He warned ominously: "If Dr M Mackenzie cannot assist and cure it there is no chance of recovery save in the operation known as 'laryngotomy.' It would have to be performed under far less favourable conditions than would have been the case fourteen days ago. Therefore, my only hope is that Dr Mackenzie may be right in his opinion and that his treatment may be successful, for we have nothing else to suggest."'

Frederick does not seem to have had any say in the decisionmaking, and it seems that he was kept in ignorance as to the true state of affairs by his wife and his doctors, although just about everyone else (Bismark, the kaiser, Queen Victoria) seemed to know what was going on. The crown princess did not believe and probably did not trust the German doctors. She wrote to Queen Victoria: "I cannot bring myself to believe that the German doctors are right! ... I have one instinctive feeling that [the fears of the German doctors] may not be founded on any real facts, but the doubt is very disagreeable and wearing, especially as it must be so carefully concealed from the dear patient, who is oftentimes much depressed." Hardly surprising.

\section{Prince opted for tracheostomy}

On 14 June Fritz and Vicky went to England to take part in Queen Victoria's golden jubilee celebrations where the tall, bearded Fritz cut a dashing figure in white uniform, silver breastplate, and eagle crested helmet in the jubilee parade from Buckingham Palace to Westminster Abbey. In all they spent three months in England and Scotland, and in their presence Queen Victoria knighted Morell Mackenzie for saving her son in law's life. Although their presence was required in Berlin as the nonagenarian Kaiser William I was declining, Fritz and Vicky went first to the Tyrol and then to Venice and finally to San Remo on the Italian coast, where they took the "very expensive" Villa Zirio overlooking the Mediterranean.
At San Remo Frederick's condition deteriorated and Sir Morell Mackenzie was sent for. On 6 November Mackenzie realised that the German doctors' diagnosis had been right all along and when asked directly by Fritz if he had cancer replied: "I am sorry to say, sir, that it looks very much like it, but it is impossible to be certain." After further consultations between the doctors, and 11 months after his symptoms had begun, the patient was given a say in his management for the first time; he was given the choice of total removal of the larynx or tracheostomy. He opted for the latter. But even that was not the final word on the matter.

On 13 November the 91 year old kaiser, learning of his son's decision, sent for eight of the German doctors who had been looking after Frederick. He asked them two questions. Should the radical operation be advised in spite of Frederick's refusal; and why, when the operation was abandoned in May, was it suggested again at such a late stage in the illness? To the first question they answered that as the operation was so dangerous the patient must decide, and to the second they replied that "the responsibility for its nonperformance until too late had been incurred by that physician who had overlooked, nay, even denied, the increase of the growth"2-namely, Morell Mackenzie. The German press was furious. The crown prince of Germany would die because of the mistake of an English doctor while the opinion of the German doctors who had been correct was set aside.

\section{Emergency tracheostomy}

Meanwhile Frederick spent his days in his dressing room, sucking ice and wearing ice bags around his neck day and night, and Professor Bergmann's assistant, Dr Bramann, was sent to San Remo should an emergency tracheostomy be required. The world watched with interest as events unfolded in Germany. Would the elderly emperor, obviously now in decline, die before his son suffocated? On 9 February 1888 Bramann performed the long deferred tracheostomy at San Remo and on 9 March William I died in Berlin.

The Emperor Frederick returned to Berlin to begin his 98 day reign. By April the tracheostomy site was indurated and surrounded by fungating tumour. On 12 April Frederick was deeply cyanosed and had stridor which could be heard in the next room. Professor Bergmann changed the tracheostomy tube in the presence of Mackenzie. Bergmann described what happened next. "I could not, however, make my way with the cannula, whilst the exalted patient's difficulty of breathing became still greater and more alarming. I, therefore, tried, after dipping my hand in a bowl of carbolic acid solution which was standing near, to push aside the fungosities with my finger, and to reach the tracheal opening and fix a hook there. After I had done this, and when I was holding the hook in my hand, Bramann passed a ... cannula into the trachea. The emperor breathed easily and freely." ${ }_{4}$ Frederick had a violent attack of coughing and bled profusely for some time from the tracheostomy. Mackenzie accused Bergmann of ill treating the emperor and making a false passage in the neck. He did not hesitate to say that Fritz had received his death blow at the hands of Bergmann.

\section{Parting of the ways}

This was the parting of the ways for Mackenzie and Bergmann, and on 30 April Bergmann retired from the case. Early in June Frederick moved to the Neue Palais where he had been born. Although dying, he struck a blow for German liberalism by sacking Puttkamer, the minister for the interior and one of Bismark's henchmen. ${ }^{5}$ By 13 June Frederick's condition was deterio- 


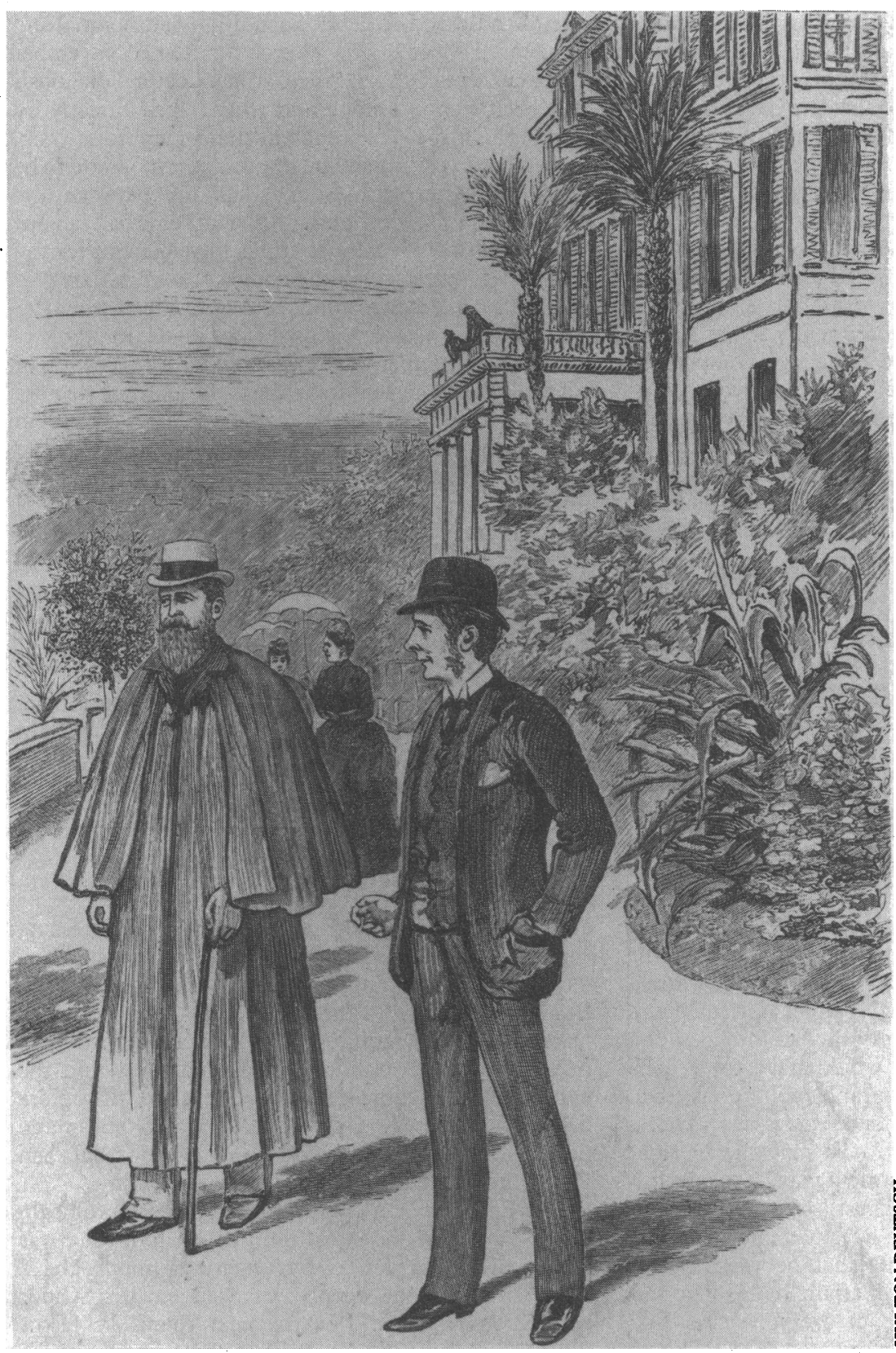

The new German emperor, Frederick III, in the garden of the Villa Zirio at San Remo with his English physician, Sir Morrell Mackenzie. Published in "The Graphic," 17 March 1888, Frederick lived until 15 June, reigning for 98 days; his son William, "the complete Guards Officer," succeeded him

rating rapidly. He was being fed by tube and the fungating tumour was causing an awful smell. Vicky wrote: "My poor darling [is] so changed! $\mathrm{He}$ is a perfect skeleton now and his fine thick hair is quite thin. His poor throat is such a painful and shocking sight that I can often hardly bear to look at it. ... It is very difficult to keep the air in the room pure."2 Two days later, at 1100 am on 15 June 1888, Emperor Frederick died.

The Neue Palais was immediately surrounded by red uniformed, armed hussars, ordered there by the new kaiser, William II, who was the embodiment of everything his parents disliked. His father had ruefully referred to him as "my son, the complete Guards
Officer."s Against the pleadings of his mother, William ordered that a postmortem examination be performed on his father's body to verify cancer and embarrass the English, particularly his mother and Morell Mackenzie. Vicky appealed to Bismark, who refused to see her. She countered by refusing to attend the state funeral of her husband. ${ }^{5}$

\section{A different outcome?}

It is doubtful whether early surgery would have significantly altered the outcome. The results of thyrotomy were poor. Butlin, reviewing the literature in 1883, commented: "Not the slightest encouragement is afforded by these accounts to induce one to perform the operation of thyrotomy for the removal of carcinoma, whether extrinsic or intrinsic. The disease is evidently far too deeply seated to admit of removal by so slight an operation." "Had Frederick lived, relations between Germany and Britain might have been different and the slaughter that was the first world war might never have happened. What is amazing is how little input Frederick had into the decisionmaking about his own medical management.

One month after Frederick's death the imperial press in Berlin published a pamphlet entitled Die Krankheit Kaiser Friedrich des Dritten in which Bergmann and Gerhardt described in detail the late emperor's illness. The $B M F$ of 13 October 1888 commented that the German pamphlet "practically amounts to a charge of malpraxis against Sir Morell Mackenzie." Undaunted, Mackenzie countered with a book entitled The Fatal Illness of Frederick the Noble which contained no less than 21 illustrations of his expatient's larynx.' In his book Mackenzie went out of his way to prove that the German doctors were incompetent and that their clumsiness (especially the incident with the tracheostomy tube on 12 April) had caused Fritz unnecessary suffering and had hastened his death. ${ }^{4}$ The $B M \mathcal{F}$ again commented that both accounts "are disfigured by personalities which are quite out of place in a scientific controversy."

On 10 January 1889 Morell Mackenzie was censured by the Royal College of Surgeons for violating confidentiality and unethical conduct. He was also summoned by the College of Physicians, but he declined to appear before it and asked that his name be removed from the roll. ${ }^{3} \mathrm{He}$ remained in private practice but bitterness and controversy destroyed his health and he died, aged 57, on 3 February 1892. After his death it was revealed that Queen Victoria and the prime minister, Lord Salisbury, had insisted that Mackenzie's response to his critics should be to the general public and not just the medical profession. ${ }^{3}$ The Empress Victoria (Vicky) died in 1901 shortly after her mother, Queen Victoria.

1 Von Bismark O. Bismark, the man and the statesman: reflections and reminiscences. London: Smith, Elder, 1898:331.

2 Ponsonby F, ed. Letters of the Empress Frederick. London: Macmillan, 1928. 3 Thorek M. Surgeons and events. Sir Morell Mackenzie 1835-1892. Fournal of International College of Surgeons 1945;8:555-8.

4 The case of the late Emperor Frederick. BMF 1888;2:836-41.

5 Massie RK. Dreadnought. London: Jonathan Cape, 1992:38-45.

6 Massie RK. Dreadnought. London: Jonathan Cape, 1992:38-45. $61-87$.

7 Mackenzie M. The fatal illness of Frederick the Noble. London: Sampson Low, Marston, Searle, and Rivington, 1888. 